\title{
Development of Design Expertise by Architecture Students
}

\author{
Adedapo Adewunmi Oluwatayo \\ Covenant University, Nigeria \\ dapo.oluwatayo@covenantuniversity.edu.ng \\ Isidore Ezema \\ Covenant University, Nigeria \\ isidore.ezema@covenantuniversity.edu.ng \\ Akunnaya Opoko \\ Covenant University, Nigeria \\ akunnaya.opoko@covenantuniversity.edu.ng
}

\begin{abstract}
What constitutes design ability and design expertise in architecture? Which categories of design expertise can be identified amongst architecture students? And which input factors differentiate one level of expertise from another? These questions were addressed in a survey of architecture students in Nigeria. Based on the results, students were classified as: novices, advanced beginners, competent and proficient design students. Also identified were five areas of design ability or competency, which include innovation and knowledge adaptation. The findings of the study presented in this paper suggest the need to encourage novice design students to use academic resources and spend more time on the analysis and synthesis stages of design so as to progress to higher levels of expertise. Other factors that can be harnessed to enhance development of expertise from one level to the next were also identified.
\end{abstract}

\section{Keywords}

architectural design; design competencies; design expertise; design education; expertise development

\section{Introduction}

The architect is one of the professionals critical to the construction industry. In practice, the architect provides a range of services ranging from design, contract administration, and renovation to project management. Design, however, remains the core competence of the architect. The issues of employability of architecture graduates often lead to concerns about the effectiveness of architectural education in developing expertise of architects, a major part of which is design.

Professional architects undertake their education in architecture schools where they are trained in the art of design, among other things. This is in line with the fact that the major role of education in any field is to guide students in the development of skills necessary for professional practice (Meijers \& Kuijpers, 2014). Skill in this context refers to the ability to perform a certain task. The ongoing process of acquisition and development of relevant skills for mastery in a particular domain has been described as the process of developing expertise (Sternberg, 1999). Higher education institutions take in novices and attempt to train them to be fit for practice in professional domains. Consequently, higher education institutions are under pressure to produce graduates with 
a knowledge base that would not only have a right fit with practice but also equip them to carve out a niche for themselves.

Training students to develop expertise in any field cannot start without an understanding of the abilities that are essential and the conditions for expertise, in this case, in the field of architectural design. In addition, as noted by Cardella, Atman and Adams (2006), one must understand how students "learn" design. It is only by doing this that students can be supported in developing their own design processes. It is noteworthy that expertise is not only acquired through formal education as observed by Boshuizen (2003), there is also an implied role of the individual in the development of design expertise. Bjorklund and Eloranta (2008) similarly asserted that expertise is more of a product of experience than of innate abilities. These experiences are not just limited to classroom assignments but also include personal investments of the individual (Kirschner, Carr, van Merriënboer and Sloep 2002). These personal investments are further influenced by other factors ranging from resources to motivation. This suggests the importance of the point of view of the student in giving insight into the inputs that aid their expertise development, in particular, those inputs based on the characteristics of the individuals, the exigencies of the task and the resources available in the environment (Phillips, Keith, Renshaw, \& Portus, 2010).

Many of the earlier studies of expertise have been carried out in fields other than architecture and, in fact, very few of these studies were in the broader field of construction. Related studies in this field were mostly on competencies, for example, Zanon (2014) focused on the competencies needed by planners while Alroomi, Jeong and Oberlender (2012) focused on cost estimators. Competencies do not necessarily translate to expertise. This is because, while competencies, also referred to as abilities, imply the requirements that an individual must meet to properly perform a specific task, expertise describes consistent superior performance in a particular domain. It is therefore essential that a person does more than acquire skills, that person must use the skills outstandingly well. This implies a progression from a starter or a novice to an expert, which education is meant to address and a process that it initiates.

The few studies that have addressed expertise in architecture investigated the processes underlying expertise (Peeters, van Tuijl, Reymen \& Rutte, 2007). These were mostly protocol studies which employed the Critical Incidence Technique (CIT). With the CIT, respondents are expected to recall a specific event and report those events in their own words. The contents of those responses are then content-analysed and used to categorise the described incidents using themes and subthemes. In expertise studies that investigated design expertise using CIT, respondents were asked to recall the processes they followed in carrying out a particular design. These processes were then used to classify the respondents according to the level of expertise inductively or deductively. Although these studies shed light on the processes that differentiate the novice from the expert, there remains a need to find out the factors that can be employed by academia to enhance the development of design expertise. This may necessitate the investigation of the characteristics of students, namely their learning inputs as well as motivation, as has been done in the fields of sport (Baker \& Horton, 2004) and interior design (Smith, 2015). This would help in developing future professionals who are fit for architectural practice. In this research, therefore, the inputs that help students to develop necessary design expertise are investigated.

A study of this nature is important as it will aid academics who train architecture students in knowing which inputs should be emphasised to support students in developing their expertise in design. It will also shed more light into what constitutes expertise and how novices can be helped to develop the same skills as experts. Expertise is subsequently discussed in its general nature and in the specificity of design expertise as elucidated in literature. The concept of expertise development is discussed. This is in terms of the processes that an individual engages in becoming an expert in a specific field. This is also related to the field of architecture. The research methods adopted in the study are thereafter discussed, followed by the key findings according to the research questions raised. Conclusions are drawn from the findings of the study. 


\section{Nature of expertise}

Expertise is the foundation of extraordinary or superior human performance and it manifests at the individual, organisational and societal levels. It has been defined as consistent superior performance of an individual in a particular area or domain (Ericsson \& Lehman, 1996). Johnson (2005) described the expert as one who possesses knowledge in a specific domain and knows how to deploy this knowledge. Knowledge refers to the information on the domain that the individual has acquired. A common factor in these definitions is that expertise is domain-specific. In facts, early expert-novice studies indicated that experts are known to excel in particular domains. The domain-specific nature of expertise implies that an expert in the game of chess may not also be an expert in the game of soccer.

The study of expertise started in the 1920 s with studies from typewriting and chess. Since that time, several studies have looked at the concept in diverse fields. These include music, mathematics, physics, nursing, typing, computer programming, second language, driving, medical diagnostics (Johnson, 2005). However, the classic studies on expertise were carried out in the game of chess. This has been attributed to the fact that chess has been a domain for cognitive science for a long time (Gobet, 1998). Since the first study, conceptualisations of expertise have varied leading scholars to posit that expertise is a multi-dimensional construct. Different theories of expertise have therefore been proposed for the field of expertise.

These theories, according to Germain (2008) are the "great man," traits, behavioural, situational and transformational theories of expertise. The assumption of the "great man" theory is that experts are born and not made while the "traits" theory focuses on the inherent traits of expertise in individuals. Genetic traits or innate abilities have been the subject of many studies as noted by Gobet (2013). In contrast to the "great man" theory, the behavioural theory posits that instilling expert behaviours in individuals can make them become experts. The transformational theory, on the other hand, views expertise as a social construct. It posits that people are more likely to perceive someone who inspires them as an expert.

The foregoing theories have however been criticised for ignoring situational specifics. When it comes to developing expertise, the situation is important. This has led to the systems approach of studying expertise and subsequently the contingency theory. Through systems theory, acquisition expertise is conceptualised as consisting of interrelated parts influenced by the environment. Expertise is therefore an open system where the individual, the tasks and the external environment interact to produce superior performance in a particular domain. The contingency theory of expertise extends this theory by stating that the interaction of interrelated parts may take varied form, leading to varied levels of expertise. It adds the "it depends" to the relationship between the parts of the system and the output. This theory states that the best action of the expert depends on a range of situations. As a result, varying characteristics define the expert. The development of expertise is to be a function of how innate characteristics interact with practice, time and other factors (Gobet, 2013). The varying interaction of personal constraints of individual learners and the environment suggest that one may not expect common pathways to expertise. It is therefore of interest to identify those inputs on which acquisition of different levels of expertise depend.

Scholars have attempted to list the characteristics by which experts may be identified. One recurring characteristic, according to Bjorklund and Eloranta (2008), is that experts have a large knowledge base which is better organised, accessed faster and used more efficiently than nonexperts in performing the skills of their domain. Bjorklund and Eloranta (2008) arrived at this definition from interviews with experienced product developers. This characteristic has also been agreed to be true for experts in architectural design (Cross, 2003). Other characteristics used in literature are superior cognitive abilities and efficient self-monitoring. Tagg (2007) contended that experts employ self-regulation in their domain of expertise to achieve continuous improvement, that is, the input of the individual may lead to transitions from one level of expertise to the other. This is probably an indication of the dynamic nature of expertise. 
Lazzara et al. (2010) further described experts as those who do not go through detailed analysis in the course of resolving problems in the domain of expertise. Rather, heuristics have been found to be a distinguishing factor in early researches on chess players suggesting that experts innovatively apply knowledge, with considerable flexibility, and draw on the similarities of current situations with past experiences. The expert may therefore be expected to be able to identify, understand and interpret clues that are relevant to problem currently being solved. Another attribute that characterises the expert, according to Tagg (2007), is a pursuit of knowledge building as a learning goal compared to the goal of task completion adopted by non-experts. This is regarded as an indication that the experts take personal responsibility for their learning. Tagg (2007) further observed that there is an intermediary group that adopts the instructional goal that entails not just carrying out assignments but learning what the assignment is meant to teach. These suggest that there are conditions under which one is considered an expert in a field.

Mieg (2009) identified conditions that may come to play when the concept of expertise is considered. These conditions are described as the factors that should be evident for a person to be regarded as an expert in a field. The conditions include superior performance, deliberate practice, cognitive adaptation, domain specificity and the "10-year rule." Superior performance is described as an outstanding feat in a particular domain while the deliberate practice condition entails extended practice of tasks in the related domain. Cognitive adaptation represents adaptations of skills and knowledge to solve problems in the domain. The conditions of domain specificity represented the limit of expertise to a particular domain, as expertise in a domain cannot be transferred to another domain. The long-term requirement of expertise development is framed as the "10-year rule." Professional engagements, evident in commitment and passion for the task constituted the other conditions for expertise that were identified. These conditions were subsequently reduced to excellence and professionalism. Mieg's (2009) research was, however, carried out amongst environmental experts in ten fields, including engineering.

\section{Expertise in design}

The expert in design can also be known by the display of certain competencies. Cross (2001) put this succinctly by noting that experts in the field of design display special competencies for perceiving, formulating and solving design problems. These competencies are referred to as design ability in this study. Bakarman (2005) further noted that, when students learn design, the ability that is being developed is the ability to use knowledge, skill and attitudes necessary for effective behaviour in a specific professional, social and learning situation. Tagg (2007) corroborated this by defining an expert as one who has acquired knowledge and skills in a particular domain and progressively applies the knowledge creatively towards finding solutions to problems. The skills components include: task clarification, concept generation, evaluation and refinement, as well as detailing design. Awareness of goals, constraints, and strategies used to generate design constitute the knowledge component. The attitudes component, on the other hand, includes abilities to gather appropriate information, acquire experiences and use solution-driven approach to handle design problems.

Cross (1990) identified eight core features of design abilities. These are: (i) production of novel, unexpected solutions; (ii) tolerating uncertainty; (iii) applying imagination; (iv) use of graphics as means of problem-solving; (v) resolution of ill-defined problems; (vi) adoption of solution-focused strategies; (vii) employing abductive/productive/appositional thinking; and, (viii) use of nonverbal graphic/spatial modelling media. The expert designer in the field of architecture is therefore expected to have superior grasp of each of these areas in handling design problems. These are the abilities that are investigated in this study in the context of architectural design.

These abilities are often evident in the ways that the individual handles a design problem, referred to as the design process. Design problems have to be identified and properly defined, as such problems are often ill-defined. One of the reasons for this is because design clients may often not have a full grasp of their requirements. As such, the designer is expected to properly understand the problem so as to re-construct it in clear terms. It would therefore appear that design problems 
are far less constrained when compared with problems in other fields (Svihla, Petrosina, \& Diller, 2007). These design problems often have multiple solutions, with designers adopting varying methods at arriving at their designs. The design process followed by the designers thus marks them as either experts or non-experts.

Beckman and Barry (2007) identified two generations of design method. The first is the scientific or sequential method which adopts a bottom-up approach (Bayazit, 2004; Jungersen \& Hansen, 2014). The assumption is that every design problem can be broken down into smaller well-defined problems. The small tasks are then performed by experts and the outcomes are synchronised. Early design cognition studies tended to treat design in this way, that is, as a pure problem-solving activity. The second is the iterative method where parameters of a design problem are explored simultaneously with possible solutions. The designer does not first define the problem. In fact, a potential design solution can help in defining the problem. Instead, solutions are explored to assess their appropriateness for given problems. This approach is therefore said to be solution-driven rather than problem-led. With this approach, the solutions that are proposed often remind the designer of other issues to consider (Dort \& Cross, 2001).

The foregoing tendency gives rise to what has been referred to as opportunistic design in which designers follow a temporary train of thought that facilitates partial solutions at little cognitive cost (Guindon, 1990). In carrying out design functions, the designer also relies on experience. The exceptional designer is therefore considered as one who has been exposed to a large number of examples of problems and solutions that occur in their domain allowing them to easily draw from a large reservoir of knowledge without necessarily being fixated (Cross, 2001). Svihla, Petrosino and Diller (2007) also noted that experts in design used the breadth-first approach, considering fewer alternatives but paying more attention to constraints, while novices in design were more likely to use the depth-first approach, and employ trial and error which results in considering more solution alternatives.

The generic model of expertise identified seven levels of expertise: novice, advanced beginner, competent, proficient, expert, master and visionary (Cross \& Lawson, 2005). Lawson and Dorst (2005) called for caution in applying this model directly to the field of design noting that problems in the field of design are highly situated and each is entirely unique. In addition, there are relatively few rules in the domain of design.

Lawson and Dorst (2005) added an initial level to the generic model of expertise, namely, the naïve level, which is characterised by high incidences of routine copying. The designer at this level has little knowledge and experience in the field of design. They can however recognise superficial attributes of designs that they can copy although they may not understand the principles. Ordinary people who perform design tasks in their day-to-day life are placed in this category. First year undergraduate students of design are also grouped under the novice category. The novice in design is most likely to follow strict procedures in dealing with design problems, referred to as the depthfirst approach (Cross, 2004). With little experience that can be relied on, the novice draws from precedents. Unlike the naïve designer, however, the novice searches for principles in the precedents. The advanced beginner is able to identify exceptions to the rule and work as the situation requires. Designers at this level adopt fewer standard solutions as they attempt to meet the requirements of each design. At this stage, the advanced beginner has also acquired the language for discussing and critiquing designs.

Lawson and Dorst (2005) further noted that the graduate of design may fall in this category. The competent designer can also identify exceptions to the rule and deal with wide range of design situations. In addition, however, the competent designer uses the hindsight of previous experience to select design goals to be pursued and works out the modalities for achieving such goals. At this stage, the designer is able to also draw up briefs and understand the needs of users.

The next level of expertise is the proficiency level when the designer easily identifies the basic issues and reasons out what to do. The proficient designer sees the bigger picture that the 
competent designer does not. The proficient designer can solve routine design problems and is often sufficient for the client, although some solutions may be innovative. Graduates with some professional experience are expected to be proficient.

It is believed that designers at levels higher than the proficient produce works that go beyond client requirements and may generate precedents that other designers consult. The attainment of the expert, master and visionary levels depend on the ambition, personality, mentality and insight of the individual. The designer at the expert level is characterised by ability to respond to situations intuitively without extensive reasoning or going through the problem-solving stages. There is therefore little cognitive analysis as design situations are automatically recognised. The expert in design is known for certain approaches and guiding principles, which have been developed over time. At the master level, the designer becomes more innovative, although, they still follow their set of guiding principles. The visionary designer develops new ways of doing things. These new ideas often take precedence over practicality of construction meaning that, sometimes, the works of visionary designers are never realised but may only feature in exhibitions and competitions.

\section{Development of expertise}

The progression from a novice to an expert is of importance to educators. How can educational institutions help a novice develop skills of an expert? How does the novice, who simply applies rules according to Dreyfus and Dreyfus (1986), become one who has more ownership of the process? In order to develop the design skills of students, they are exposed to practical design problems through design exercises. The traditional design studio is the avenue for dissemination of relevant knowledge and learning of design skills. The design studio, according to Reimer and Douglas (2003), "involves experiential, immersive pedagogy based on learning by doing in a purely interactive context" (p. 194). Lawson and Dorst (2009) recognised the place of the studio in the development of design expertise in students. This is because studios are based around design projects. The studio is a place for student-led problem solving as they are expected to provide design solutions to diverse complex sets of requirements and specifications, through which they learn the act of design.

Different perspectives have been used in studying expertise development in literature. Phillips et al. (2010) categorised these into two. The first is the traditional approach while the second is a systems approach. The traditional approach is made up of the deliberate practice and the genetic makeup principles. While the genetic makeup principle views expertise from the perspective of the inherent genetic traits of the individual, the deliberate practice principle highlights the importance of time spent in structured activities. The genetic make-up principles thrive on the assumption that a person's genetic make-up influences specific behaviour and capacities, for example, Baker and Horton (2004) presented studies that have found this to be true in the field of sports. Further, Ericsson and Ward (2007) noted that reproducible superior performance might be moderated by substantial neural and physiological adaptations. It has, however, been noted that genetic advantage, without some input from the individual does guarantee expert performance. This led to the development of the deliberate practice framework.

The deliberate practice framework proposed that the efficient acquisition of domain-related knowledge and skills, and thus exceptional performance, is primarily due to goal-directed, painstaking practice (Gobet, 2012) Hence, the deliberate practice framework involves a series of activities carried out at the individual level and directed at improving performance. These activities tend to be repetitive and are designed to give feedback. The deliberate practice framework rejects innate talent as the explanation for cognitive abilities (Ericsson, Krampe \& Tesch-Romer, 1993). In the framework, innate factors were limited by motivation, general activity level and, in some kind of sports, physiological features such as height. Hence, the involvement of genetic factors is excluded in explaining individual differences in high levels of cognitive abilities (Gobet, 2012). As some studies have indicated, practice is not the only sufficient condition for reaching high levels of expertise. In Gobet and Campitelli's (2007) study of chess players, a strong 
correlation was found between chess skill and number of hours of practice. However, the high variability in the number of hours of deliberate practice of between 3,000 and 24,000 hours is an indication that other factors may be responsible for the acquisition of expertise in chess. The study also found a strong correlation between skill level and the starting age of the chess players as well as the strong proportion of mixed-handedness among chess players relative to normal population.

Hence, other factors apart from or in addition to deliberate practice may have accounted for the level of expertise displayed. In addition, neither genetic make-up nor deliberate practice absolutely guarantees expertise; it depends on the situation of the individual. This has led to the birth of the systems perspective - the second perspective used in the study of expertise. It is based on the assumption that expertise can be achieved in diverse ways. The systems approach is predicated on identifying factors that contribute to expertise development. These factors are not just limited to deliberate practice and inherent genetic traits; it takes into consideration the task and the environment. The basis of the systems perspective is that expertise development is a complex system where individual dynamics interact with key constraints to give varying expert performances. In fact, Bartholomew (2008) opined that expertise is like a jigsaw puzzle made up of information, intellectual skills, beliefs, interpersonal skills and body skills. Expert performances are predicated on trade-offs between specific and diverse behaviours. Put succinctly, expertise development is described as a complex evolving system with transitions in performance resulting from interactions between the seeking of new challenges, rich support network, self-discovery and exposure to rich learning design.

Moon, Kim and You (2013) identified three components of the expertise system. These were the self, practice and the meta-systems. While the self-system captures the psychological state of the individual the practice system incorporates the task with which the individual learn to play relevant roles. The meta-system is external to the individual and entails the external constraints on individual learners. It may therefore be inferred that the acquisition of expertise is determined by the varying interaction of the individual with the practice and other factors (Gobet, 2012). Phillips et al. (2010) also described the expertise system as the interaction of individual dynamics with the task and the environment to achieve superior performance. Each person is expected to harness the variability in the environment and the task in different ways. This suggests that expertise may develop in unique ways. According to Caley, O'Leary, Fisher, Low-Choy, Johnson and Mengersen (2014), when the behavioural requirement of a task is closely matched with the intrinsic dynamics of the individual, the rate of expertise development is enhanced. This suggests that some matches of individual characteristics with the task requirement can result in enhanced expertise development. With the identification of the key factors that facilitate the development of expertise, these factors (referred to as constraints by Caley et al., 2014), can be manipulated to encourage the exploration of options that could lead to higher levels of expertise in relevant field. In other words, it is believed that phase transition in individual expertise performance can be induced. The individual factors could be psychological, physiological or anthropometrical (as in certain sports). The environmental factors include socio-cultural such as family support, and access to facilities. The task factors are specific to the field of study or practice.

Some of these factors have been found to influence the development of expertise especially in fields such as sports (Baker \& Horton 2004), engineering design (Cardella, et al., 2006) and interior design (Smith, 2015). Such factors include starting age, familial support, instructional resources and other contextual factors (Baker, Horton, Robertson-Wilson \& Wall, 2003); availability and use of instructional resources such as books (Cardella, et al., 2006) and emotional climate of the design studio, complexities of design juries and power differentials in student/ instructor relationships (Smith, 2015).

The influence of these factors may not be applicable for all levels of expertise. In fact, this is a major assumption of the systems approach. There is, clearly, no single way of achieving expertise. Dorst and Reymen (2004) found that the effectiveness of support depends on the learner's level of expertise. Similarly, as Gobert (2012) observed, in addition to time spent in practice, other factors also matters in the development of design expertise. 
In this study based on the perceptions and experience of architecture students, the development of expertise is conceptualised as a function of environmental, task and individual factors in line with the systems perspective. This is in line with Phillips et al.'s (2010) description of design expertise development as resulting from exposure of students to optimal learning designs, rich support networks, self-discovery of students and quest for new challenges. The concept sees the individual, task and environmental characteristics as essential inputs into the development of design expertise (as illustrated in Figure 1). Differentials in expertise level are considered as resulting from differentials in these inputs. The inputs that differentiate the various levels of expertise are thus investigated in this study.

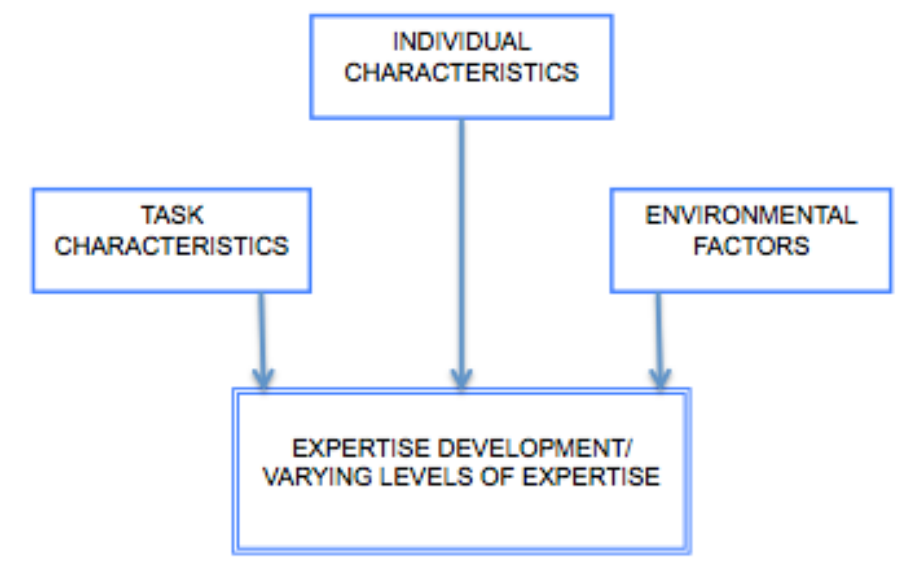

Figure 1. Conceptual framework

\section{Approaches used in the study of expertise}

The two main approaches to the study of expertise are the study of experts (expert-performance approach) (Mieg, 2009) and expert-novice comparative study (Cardella, et al., 2006). Researchers have also used both cross-sectional (Bjorklund \& Eloranta, 2008; Cardella, et al., 2006) and longitudinal survey (Adams, Turns \& Atman, 2003; Smith, 2015) research designs. Crosssectional studies are based on studies carried out at a point in time while longitudinal studies are based on data collection extended over a period of time and seek to investigate the effect of time on the observed phenomenon. While the cross-sectional method has the advantage of producing fast and extensive data from which generalisations can be made, the method has been criticised for its inability to provide information on how expertise develops over time. Longitudinal studies fill this gap but are neither fast nor extensive. The probability of making predictions based on longitudinal studies is low and Johnson (2005) observed the scarcity of longitudinal expertise studies. Consequent to this, the cross-sectional method was adopted in this study to make predictions on inputs that may be improved to enhance the development of design expertise.

Expertise in the domain of design has been studied in some detail (see, for example, Cross, 2001, 2003, 2004; Dorst, 2011; Dorst \& Reymen, 2004; Popovic, 2004; Lawson \& Dorst, 2005). Case study method is sometimes used to study students' design processes on a particular design project, through observation (Popovic, 2004). A step further is the verbal protocol method, often used with the interview method, where respondents are prompted to give verbal reports through reflection on mental processes or by narration of events, experiences and life histories (Cardella, et al., 2006; Cross, 2003; Smith, 2015). The card sorting method that is also sometimes used involves observation of respondents while they sort concepts. The experimental method is rare and used in the field of psychology for expertise studies. These are all methods used in studying the cognitive processes of developing expertise. The focus of this study is identification of inputs that aid the development of design expertise in students and a questionnaire would be more appropriate as the 
responses of students to standard questions are expected.

Popovic (2004) and Johnson (2005) suggested that expertise might be operationalised by the number of years of experience. The use of the number of years as a measure of expertise has been contested by other researchers who noted that there are persons who are experienced in domains where they still remain more or less novices. In addition, the number of years does not necessarily translate to experience. Since there are characteristics by which level of expertise are identified in literature, students may be categorised on their responses on how they fit into the descriptions. Expertise development is viewed in this study as a product of students' personal characteristics, task characteristics and environmental factors.

\section{Research methods}

The aim of the study described in this paper was to investigate the development of design expertise in architecture from the perspective of students. Four research questions were investigated:

1. What constitutes design ability in architecture?

2. What are the conditions for design expertise in architecture?

3. Which categories of design expertise can be identified amongst architecture students?

4. Which individual, environmental and task characteristics account for the variances in the levels of expertise among the students?

This study conducted a cross-sectional survey of architecture students based on their perceptions rather than self-reports on a particular design task. The survey method was adopted to ensure rapid and extensive collection of data peculiar to architectural design expertise development. The population of study included students from the second to the fourth undergraduate years as well as students in the two classes of the Masters levels. This is because the University in the study offered the Bachelor of Science degree. In Nigeria, universities offer either a four-year Bachelor of Science degree in Architecture or a five-year Bachelor of Technology degree in Architecture. Students in the first year of their course were exempted from the study because they had not yet started the design studio course. The study population included 216 students in the undergraduate levels and 68 students in the Masters levels.

The self-administered questionnaires were distributed to all participants in the study, that is, students from three undergraduate and two postgraduate courses in architecture. The questionnaire consisted of five parts. The first part aimed at collecting data on the students' characteristics.

The second part of the questionnaires collected data on the students' design abilities. The students were asked to indicate how well they have developed the design abilities identified by Cross (1990) that they have developed. This was done on a five-point Likert scale where 1 represented "not developed at all" and 5 represented "highly developed." The fourteen-variable design ability scale used in investigating design ability was found to be reliable (Cronbach's Alpha = 0.879).

The third part of the questionnaire investigated the conditions for expertise using the questions developed by Mieg (2009). Although the instrument was tested on environmental professionals in fields including engineering, the instrument is tested on students to assess the applicability. As in the Mieg's (2009) study, the conditions for expertise were measured by self-assessment. The students were asked to indicate the likelihood that their colleagues would rate them "high" in certain areas, for example, being one of the top 10 designers in class, being completely absorbed in the design work and knowing how to get to the core of the design problem. The responses varied from "very unlikely" (coded as 1) to "very likely" (coded as 5). The responses to the 9-item scale were subjected to a reliability test. The result shows that the items did better than chance in defining expertise (Cronbach's Alpha $=0.883$ ). 
In the fourth part of the questionnaire, the students were asked to indicate how strongly they use some processes in arriving at their designs solutions. A five-point scale was also used where 1 represented "strongly disagree" and 5 represented "strongly agree." These questions were coined from the characteristics of each level of expertise derived from the literature. There were 47 questions in this section (Cronbach's Alpha $=0.864$ ). These questions were adapted from the previously cited studies of Lawson and Dorst (2005) and Cross (2004). The data obtained in this section were used in categorising the students into levels of expertise. The student cases were classified based on common approaches to design in a cluster analysis.

In the fifth part of the questionnaire, there were questions that elicited information of the proportion of time spent on different aspects of the design identified by Cardella et al. (2006). The time spent was measured relative to other activities in the design process for a particular design. For every design, each student was given a timeline for completion. The students were asked to indicate the proportion of time spent on design activities relative to the timeline for their design projects. This was done on a scale where 1 represented "no time at all" and 5 represented "almost all of my time." There were other questions in the fifth part of the questionnaire related to the individual, environmental and task characteristics as viewed by the participants. These included availability and use of learning resources, relationship with tutors, motivation, time spent on different activities of design and parental support. There were 52 questions in this section. Of the 285 questionnaires distributed, 153 were usable, representing a valid response rate of $53.7 \%$. The data obtained were analysed using descriptive statistics, analysis of variance, principal component, cluster and regression analyses.

\section{Results}

Most of the students who responded to the questionnaires were either in the third $(30.1 \%)$ or fourth year (32.7\%) while $17 \%$ were in the second year. A total of $20.3 \%$ were in the Masters courses. More than half of the respondents were male (64.4\%) as shown in Table 1. Very few of the students were less than 17 years old (2\%) while the majority $(72.2 \%)$ were aged between 17 and 21 years. This is understandable since the average age for graduation from secondary school in Nigeria is 17 years. Most of the students were found to have started the study of architecture between 16 and 17 years. The studio grades investigated in this study were the grades of the preceding semester of the year under consideration. The studio grade most prevalent among the students was the B grade with 4 out of the total 5 points. This grade was between $60 \%$ and $69 \%$. The students were also asked to indicate the number of hours they spent designing on average during the semester. The result also shows that most of the students (73.9\%) spent between 2-6 hours each day designing with $16.3 \%$ of the students spending less than 2 hours. A further exploration of the data shows that the number of hours spent designing was significantly related to the year of study (chi square $=0.017$, degree of freedom $\mathrm{df}=16$ ). None of the students in the second year spent more than 6 hours designing with most spending up to four hours a day. Higher percentages of the students in senior years spent more than four hours designing each day. 
Table 1. Profile of respondents

\begin{tabular}{|c|c|c|}
\hline Variable & & $\%$ \\
\hline \multirow[t]{5}{*}{ Year of study and course } & 200 Level ( $2^{\text {nd }}$ year $)$ & 17.0 \\
\hline & 300 Level ( $3^{\text {rd }}$ year) & 30.1 \\
\hline & 400 Level ( $4^{\text {th }}$ year $)$ & 32.7 \\
\hline & MSc I (Masters) & 9.2 \\
\hline & MSc II (Masters) & 11.1 \\
\hline \multirow[t]{2}{*}{ Sex } & Male & 64.4 \\
\hline & Female & 35.6 \\
\hline \multirow[t]{4}{*}{ Age } & 14-16 Years & 2.0 \\
\hline & 17-19 Years & 42.4 \\
\hline & 19-21 Years & 29.8 \\
\hline & Above 21 Years & 25.8 \\
\hline \multirow[t]{5}{*}{ Grade in design studio last semester } & $\mathrm{F}(0$ point $)$ & 2.5 \\
\hline & $\mathrm{D}$ (2 points $)$ & 8.4 \\
\hline & $\mathrm{C}$ (3 points) & 18.5 \\
\hline & B (4 points) & 42.9 \\
\hline & A (5 points $)$ & 27.7 \\
\hline \multirow{5}{*}{$\begin{array}{l}\text { Average number of hours spend designing } \\
\text { during the semester }\end{array}$} & $<2$ hours & 16.8 \\
\hline & 2-4 hours & 48.3 \\
\hline & 5-6 hours & 27.5 \\
\hline & 7-9 hours & 4.7 \\
\hline & $>=10$ hours & 2.7 \\
\hline \multirow{2}{*}{$\begin{array}{l}\text { Offer of design subjects prior to enrolling for } \\
\text { architecture }\end{array}$} & Yes & 53.6 \\
\hline & No & 46.4 \\
\hline \multirow{2}{*}{$\begin{array}{l}\text { Offer of creative arts prior to enrolling for } \\
\text { architecture }\end{array}$} & Yes & 9.9 \\
\hline & No & 90.1 \\
\hline \multirow{2}{*}{$\begin{array}{l}\text { Offer of design subjects prior to enrolling for } \\
\text { architecture }\end{array}$} & Yes & 50.0 \\
\hline & No & 50.0 \\
\hline \multirow{4}{*}{$\begin{array}{l}\text { Rating of the level of design preparation } \\
\text { received prior to enrolling for architecture }\end{array}$} & Not prepared at all & 27.1 \\
\hline & Prepared to a little extent & 15.3 \\
\hline & Prepared to some extent & 44.1 \\
\hline & Prepared to a large extent & 13.6 \\
\hline
\end{tabular}

\section{Research Question 1}

The first research question answered in this study was to identify what constitutes design ability in architecture students. Fourteen variables had been identified (see, for example, Cross, 1990) which were subjected to principal component analysis. The essence was to identify the main factors that 
define design ability especially in the context of architecture. These are the factors that account for most of the variability in the descriptions of design ability by the students. The Kaiser-MeyerOlkin (KMO) measure of sampling adequacy was first examined and a value of $0.869(\mathrm{p}=0.000)$, shows that the principal analysis was appropriate. The results show that five factors accounted for $67.8 \%$ of the variance in the data.

Table 2. Factors that define design ability

\begin{tabular}{|c|c|c|c|}
\hline & Factors & Variables & \multirow{2}{*}{$\begin{array}{r}\text { Component } \\
\text { loading }\end{array}$} \\
\hline Factor 1 & Innovative ability & $\begin{array}{l}\text { ability to produce novel, unexpected } \\
\text { solutions }\end{array}$ & \\
\hline & & $\begin{array}{l}\text { ability to apply imagination and } \\
\text { constructive forethought to practical } \\
\text { problems }\end{array}$ & .740 \\
\hline & & $\begin{array}{l}\text { ability to tolerate uncertainty, working } \\
\text { with incomplete information }\end{array}$ & .581 \\
\hline \multirow[t]{3}{*}{ Factor 2} & $\begin{array}{l}\text { Ability adapt design } \\
\text { knowledge }\end{array}$ & $\begin{array}{l}\text { ability to employ productive/ } \\
\text { appositional thinking }\end{array}$ & .818 \\
\hline & & $\begin{array}{l}\text { ability to adopt solution-focusing } \\
\text { strategies }\end{array}$ & .783 \\
\hline & & - $\quad$ ability to resolve ill-defined problems & .518 \\
\hline \multirow[t]{3}{*}{ Factor 3} & $\begin{array}{l}\text { Adeptness in use of } \\
\text { design media }\end{array}$ & $\begin{array}{l}\text { Ability to use non-verbal, } \\
\text { graphic/spatial modelling media. }\end{array}$ & .793 \\
\hline & & $\begin{array}{l}\text { ability to use drawings and other } \\
\text { modelling media as means of problem } \\
\text { solving }\end{array}$ & .624 \\
\hline & & $\begin{array}{l}\text { - ability to communicate my ideas in } \\
\text { drawings }\end{array}$ & .503 \\
\hline \multirow[t]{2}{*}{ Factor 4} & $\begin{array}{l}\text { Integration of } \\
\text { structural, social and } \\
\text { cultural requirements }\end{array}$ & $\begin{array}{l}\text { ability to incorporate knowledge of } \\
\text { structures, building components and } \\
\text { methods }\end{array}$ & .750 \\
\hline & & $\begin{array}{l}\text { awareness of social and cultural } \\
\text { environment related to each design }\end{array}$ & .734 \\
\hline \multirow[t]{3}{*}{ Factor 5} & Ability to produce & - understanding of design concepts & .719 \\
\hline & & $\begin{array}{l}\text { ability to focus on the users during } \\
\text { design }\end{array}$ & .614 \\
\hline & & $\begin{array}{l}\text { ability to integrate technology in your } \\
\text { design }\end{array}$ & .589 \\
\hline
\end{tabular}

The first factor represented innovative ability and loaded on abilities to produce novel and unexpected solutions, apply imaginative and constructive thoughts to practical problems and tolerate uncertainties, working with incomplete information (Table 2). This factor accounted for 
$15.2 \%$ of the variance in the data. The second factor accounted for $13.7 \%$ of the variance in the data and represented ability to adapt design knowledge. This factor loaded on abilities to adopt solution-focused strategies, employ productive/appositional thinking and resolve ill-defined problems. Loading on the third factor were abilities to use non-verbal modelling media as the means of problem solving and to communicate ideas on drawings. This factor represented the adeptness of the students in using design media. The fourth and fifth factors each accounted of $12.7 \%$ of the variance in the data and represented integration of structural, cultural and social requirements and ability to produce functional design, respectively. These are the basic design abilities developed through design education.

\section{Research Question 2}

In order to answer the second research question, namely, to identify what constitutes design expertise, another principal component analysis was carried out on the responses to the 9-item questions used by Mieg (2009). The analysis was carried out because its results suggest the major factors by which a concept may be defined. The result shows that the principal component analysis was adequate $(\mathrm{KMO}=0.87, \mathrm{p}=0.000)$. Two factors were derived which accounted for $63.2 \%$ of the variance in the data. The first factor, passion, accounted for $34.4 \%$ of the variance and loaded on the students' tendency to be absorbed by their design work, working with specific focus, always striving to improve design skills and taking responsibility (Table 3 ). The second factor, proficiency, loaded on being sufficiently experienced in design, being among the top $10 \%$ designers in class and knowing how to get to the core of the design problem. Other variables that loaded on the second factor were being active in design and taking one's time to clearly understand the design problem. This factor accounted for $28.8 \%$ of the variance in the data.

Table 3. Factors that define design expertise

\begin{tabular}{|c|c|c|c|}
\hline & Factors & Variables & $\begin{array}{c}\text { Component } \\
\text { loading }\end{array}$ \\
\hline \multirow[t]{4}{*}{ Factor 1} & Passion & $\begin{array}{l}\text { that you are always completely } \\
\text { absorbed by your design work }\end{array}$ & .849 \\
\hline & & - that you work with a specific focus & .761 \\
\hline & & $\begin{array}{l}\text { - that you always strive to improve your } \\
\text { design skill }\end{array}$ & .757 \\
\hline & & - that you enjoy taking responsibility & .703 \\
\hline \multirow[t]{5}{*}{ Factor 2} & Proficiency & $\begin{array}{l}\text { - that you are sufficiently enough in } \\
\text { design }\end{array}$ & .816 \\
\hline & & $\begin{array}{l}\text { that you are among the top } 10 \% \\
\text { designers in the class }\end{array}$ & .803 \\
\hline & & $\begin{array}{l}\text { that you always know how to get to } \\
\text { the core of the design problem }\end{array}$ & .629 \\
\hline & & - that you are very active in design & .569 \\
\hline & & $\begin{array}{l}\text { - that you take your time to clearly } \\
\text { understand every design problem }\end{array}$ & .568 \\
\hline
\end{tabular}




\section{Research Question 3}

The third research question in this study aimed to identify the levels of expertise evident among architecture students. To answer this question, it was necessary to group the students according to their responses to their design processes. A cluster analysis was therefore carried out to identify naturally occurring groups of students and thus maximise between-group variations. It allowed the categorisation of the students into expertise levels in line with the characteristics of different expertise levels found in literature. The condition set for clustering was the log-likelihood distances between groups. The confidence interval was set at $95 \%$.

The formation of the clusters was determined using chi squared tests. Four clusters of the students were obtained: Advanced beginner; competent; novice; and proficient (see Supplementary Document 1 to this article).

The variables that were responsible for the formation of the first cluster of students were considering all issues before arriving at a design, taking things step by step, following a set of procedures and designing by seeing examples. The cluster was made up by $15.7 \%$ of the students who could be described as novices. They appear to learn better when they receive explanations from their studio mentors. They sometimes find it difficult to put down their ideas and do not necessarily have reasons for the lines they draw. They are, however, able to define the objectives of designs and stick to both the objectives and sometimes the initial design ideas. All the levels of expertise cut across all the years of study, with the number of novices and advanced beginners reducing at higher years of study.

About one-third (37.4\%) of the students were in the category of the advanced beginners. These students take the design processes step by step, following the same set of procedures. They thoroughly explore and interpret design problems, think more conceptually than concretely, and take time to explore, define and evaluate the design. The students in the advanced beginner category also rarely discard their first design idea.

The students in the third cluster $(32.2 \%)$ were classified as competent and also try to first understand the design brief before designing, create several sketches and try to evaluate them before making a choice. Other variables that characterise this group of students were that they have reasons for every line they draw, they also consider a wide range of alternatives and rely on their intuition in coming up with designs. They practice even when there is no design assignment but are not fast at coming up with designs. These students can be referred to as the competent design students.

Only $14.8 \%$ of the students were classified as proficient in line with the categorisations of Cross (2004) and belonged to the fourth cluster. The students in this category take their time to define the design problem, but were characterised by consistent practice, asking critical questions to identify the main issues and applying the knowledge of building components and methods as well as building structures in their designs. The students in this cluster look at the general design problem, instead of what they describe as small details. They tend to be more knowledgeable about the limitations of the designs, and interpret every brief their own way. On identifying the objectives, which sometimes include their personal objectives, they stick to identified objectives until they are all addressed. These students also consider a wide variety of alternatives before sticking to one. In order to determine if the design abilities developed by the students varied significantly with the level of expertise, a Kruskal-Wallis test was conducted on the cluster membership variable created and the factor scores of the students on design competencies. The results show that the developments of abilities to produce innovative designs (Chi Squared $\lambda=13.089$, degree of freedom $\mathrm{df}=3, \mathrm{p}=0.004)$ and adapt design knowledge $(\lambda=11.899, \mathrm{df}=3, \mathrm{p}=0.008)$ varied significantly with the levels of expertise. The students at the competent design expertise level had the highest median score on innovative ability, followed by the students at the proficient design expertise level. The students that indicated the lowest innovative ability were those in the advanced beginners' stage. The median score on the ability to adapt design knowledge was also 
highest with the students at the proficient design expertise level. This was followed by the scores of students at the competent design expertise level. The novices indicated the lowest ability to adapt design knowledge.

\section{Research Question 4}

To answer the fourth and final question in this study aimed to identify the individual, environmental and task characteristics which account for the variances in the levels of expertise among the students, a discriminant analysis was carried out. Before the discriminant analysis was carried out however, the 52 variables used in measuring the task, individual and environmental characteristics were first reduced using principal component analysis. Ten factors were identified which accounted for $55.8 \%$ of the variance in the data (see Supplementary Document 2 to this article).

The factors represented: the use of academic resources; students' self-efficacy; unfavourable relationship with tutors; motivation and time spent by the students at the design presentation stage. Other factors were design guidance, time spent at the analysis and synthesis stages and preparation prior to enrolling for architecture. The remaining factors that were derived were family support and proficiency in the use of media. The factor scores were entered as independent variables along with sex and starting age of the students in the categorical regression, which was carried out to determine the input factors that predicted the level of expertise that the students attained. The students' cluster grouping was entered as the grouping variable. The results of the discriminant analysis revealed the three functions by which the levels of expertise could be discriminated. The first function accounted for $68 \%$ of the variance in the data (eigenvalue $=1.19$ and canonical correlation $=0.74)$. The functions at group centroid (Table 4 ) revealed that this function differentiated students at the novice level from those at other levels of expertise. The students at the novice level did not use much of academic resources and spent less time at the analysis and synthesis stage of design when compared to students at other levels (Table 5). In terms of design ability, these students were less adept in adapting design knowledge. The individual characteristic that differentiated the students at this level was their relatively lower level of motivation when compared to students at other levels of design expertise. The significant environmental influence that differentiated the novices was their perceived less favourable relationship with their tutors. The component of expertise that this novices seem to be deficient in is passion.

Table 4. Functions at group centroids results of discriminant analysis

\begin{tabular}{lccc}
\hline \multirow{2}{*}{ Level of expertise } & \multicolumn{3}{c}{ Function } \\
\cline { 2 - 4 } & -2.705 & 2 & 3 \\
\hline Novice & .324 & .089 & .107 \\
Advanced Beginner & .396 & .643 & -.086 \\
Competent & .711 & .362 & -.336 \\
Proficient & & & .934 \\
\hline
\end{tabular}

The second function accounted for $22 \%$ of the variance in the data (eigenvalue $=0.39$ and canonical correlation $=0.53$ ) and differentiated students at the advanced beginner stage from students at other levels. The structure matrix (Table 5) revealed that individuals at the advanced beginner stage were mostly at the earlier years of study and expressed lower self-efficacy than other students. These competent design students were further differentiated by their propensity to spend less time on design presentation stage and their lower proficiency in the use of design media. They also demonstrated lower innovative ability. The advanced beginners were also differentiated by their low scores on the proficiency component of expertise.

The students at the proficient design stage were differentiated from other students by the third 
discriminant function that accounted for $10 \%$ of the variance in the data (eigenvalue $=0.17$ and canonical correlation $=0.39$ ). These students demonstrated high prior preparation in design, and spent more time designing per day. The proficient design students also demonstrated greater ability to integrate cultural, structural and social requirements and produce functional designs. They used more design guides and enjoyed greater family support.

Table 5. Structure matrix results of discriminant analysis

\begin{tabular}{|c|c|c|c|}
\hline \multirow{2}{*}{$\begin{array}{l}\text { Factors that differentiate students based on their } \\
\text { level of design expertise }\end{array}$} & \multicolumn{3}{|c|}{ Function } \\
\hline & 1 & 2 & 3 \\
\hline Use of academic resources & $.502^{*}$ & .255 & .009 \\
\hline Motivation & $.386^{*}$ & -.232 & .158 \\
\hline Ability adapt design knowledge & $.231^{*}$ & .210 & .171 \\
\hline Passion & $.210^{*}$ & -.040 & -.114 \\
\hline Unfavourable relationship with tutors & $-.085^{*}$ & .078 & .074 \\
\hline $\begin{array}{l}\text { Time spent by student at the analysis and } \\
\text { synthesis stage }\end{array}$ & $.036^{*}$ & .023 & .030 \\
\hline Student's self-efficacy & -.049 & $-.533^{*}$ & .310 \\
\hline Innovative ability & .092 & $.454^{*}$ & -.139 \\
\hline Proficiency & .233 & $.409^{*}$ & .042 \\
\hline Year of study & .064 & $.236^{*}$ & -.107 \\
\hline Adeptness in use of design media & -.059 & $.225^{*}$ & -.124 \\
\hline $\begin{array}{l}\text { Time spent by student at the design presentation } \\
\text { stage }\end{array}$ & .048 & $.219^{*}$ & .002 \\
\hline Proficiency in the use of design media & .124 & $.142^{*}$ & -.050 \\
\hline Family support & .012 & .074 & $.411^{*}$ \\
\hline $\begin{array}{l}\text { Average number of hours respondents spend in } \\
\text { designing each day during the semester }\end{array}$ & .093 & .171 & $.394^{*}$ \\
\hline Preparation prior to enrolling for architecture & .162 & -.089 & $-.332^{*}$ \\
\hline Ability to produce functional designs & .201 & -.040 & $-.291^{*}$ \\
\hline Integration of structural, social and cultural requirem & .165 & .189 & $.206^{*}$ \\
\hline Design guidance & .137 & .076 & $-.205^{*}$ \\
\hline
\end{tabular}

*. Largest absolute correlation between each variable and any discriminant function

\section{Discussion of results}

The development of design expertise was investigated using a sample of architecture students. On the question of what constitutes design ability, five competencies were identified: innovative ability; ability to adapt design knowledge; adeptness in use of design media; integration of structural, social and cultural requirements; and ability to produce functional designs. These competencies suggest areas that design educators should target. It would be noted that all the areas are often addressed in the courses taken by architecture students. It is however interesting to note that adeptness in the use of design media is one of the competencies identified. Over the years, design media has changed, from manual drafting to 2D software, and recently to Building Information Modelling (BIM) software. More changes are still expected with advancements in technology. Hence, there may be need to constantly upgrade courses on design media to keep students up-to-date and improve their design competencies. 
Among environmental professionals, including engineers and regional planners, the conditions for expertise identified by Mieg (2009) were professionalism and excellence. By comparison, in this study of a sample of architecture design students, passion and proficiency were the main factors and some of the variables loaded differently from Mieg's (2009) study. For example, being active, loaded with taking responsibility and striving to improve skills, were loaded with being among the top $10 \%$ designers in this study. In addition, being completely absorbed by the work, which did not load on any factor in the Mieg's (2009) study, loaded on the passion factor in this study. The test of reliability in this study gave a slightly higher result of 0.886 , against 0.78 reported in Mieg's (2009) study. This suggests that the conditions for expertise may vary based on the field in the same way that expertise is domain-specific. Bonneville-Roussy, Lavigne and Vallerand (2011) specifically noted that passion is the driving force of expertise and explains the high level of commitment displayed by experts. It has been found to be a key component of expertise in arts, music, psychology and sports. Proficiency, on the other hand, represents the ability to carry out a design task well. This result suggests the need to get the students interested in the field of study, so that they can internalise the activities, and not just go through the motions of design. This result probably brings to the fore the place of attitude and activity in the development of expertise.

The levels of expertise identified in this study are the novice, advanced beginner, competent and proficient levels. The absence of the expert, master and visionary levels amongst the students is understandable, as expertise in professional fields is often achieved after many years in practice and the participants in this study were beginning their studies and careers. In fact, Mieg (2009) believed that it takes at least 10 years' experience to become an expert while Ericsson (2006) contended that it takes between 30 and 40 years to become a master. Lawson and Dorst (2009) noted that students attain the competent expertise level at the final year studio level. At this level, students learn to interpret design challenges in their own way as they are free to give their own interpretation to designs. This is enhanced when students are introduced to contexts where they are free to create their own problems and defend their choices. It is thus believed that the other layers of expertise in design are attained in professional practice. It appears that although time is important in the development of expertise, other factors are also important.

Students at the competent and proficient levels of expertise were also found to practice outside design assessment, which suggests that the students take responsibility for their learning. In which case, they can be said to pursue knowledge-building goals as suggested by Tagg (2007). The novices and advanced beginners however rarely practice outside design assignments. It would also appear that the novice and advanced beginner design students design from first principles as suggested by Cross (2003), while the design competent and proficient students design using an iterative approach. The findings of this study also corroborate the assertion of Johnson (2005) that a person may be experienced in design but remain a novice. This is because novices were found at all levels of study, including the final Masters year, although the proportion is reduced at higher levels. This probably suggests the limitations of formal training in developing design expertise in some students. This however needs to be further investigated.

The levels of expertise were also related to two of the design abilities derived from the study. One was the ability to produce innovative designs while the other was the ability to adapt design knowledge. As would be expected, students at the proficient level exhibited the greatest ability to adapt design knowledge, followed by the students at the competent and advanced beginner. The students that exhibited the least ability to adapt design knowledge were those at the novice level. One reason for this may be that it takes time and experience to gain knowledge. Adapting this knowledge is also a function of practice.

A characteristic that differentiates the students at the proficient and competent levels from those at the advanced beginner and novice levels is their greater propensity to practise even outside class. The result for the variation of ability to produce innovative design with level of expertise was a little different. The students at the competent level exhibited the highest ability to produce innovative designs. These students demonstrated almost equal tendency to rely on intuition as the students at the proficient level. They are however not as fast, and give more consideration to the 
limitations of the design than the students at the proficient level. This probably explains why the students at the competent level demonstrated higher ability to produce innovative designs than those at the proficient level. The students at the novice level may also have exhibited greater innovative ability because they follow less strict procedures in arriving at their designs, sometime having no reasons for the line they draw. The students at the novice level are also the more aware of the limitations of their designs. What this suggests is that greater awareness of limitations of design may encourage greater innovative ability of students, as they try to design within such limitations.

As noted earlier, the influence of the inputs in expertise development may not be the same for all levels of expertise. The results of this study suggest the areas that may be addressed to encourage individuals to move from one level of design expertise to the next. To encourage architectural design students to move from being novices to higher levels of expertise, the result of the study suggest the need for the use of academic resources. This lends credence to the assertion by Cardella et al. (2006) that availability and use of instructional materials helps students in acquisition of design skills. This finding emphasises the need for the acquisition of design knowledge by students when design expertise is the goal (Bjorklund \& Eloranta, 2008; Popovic, 2004). It may therefore be implied that students of design need to be conversant with design texts if they are to develop their expertise. This is linked with the need to acquire skills in adapting design knowledge. This calls for relevant practice often facilitated by appropriate design tasks. Students at the novice level can also be encouraged to spend more time at the analysis and synthesis stage. This appeared to be in contrast with the assertion of Lazzarra et al. (2010), who noted that experts spend less time on detailed analysis.

The current research has been carried out in the field of design where problems are often ill defined and objectives are incomprehensive. As such, more experienced designers often add their own objectives, necessitating a longer analysis period, to ensure a full understanding of the requirements. In addition, students at the novice level need to be motivated and have a more favourable relationship with their tutors in order to develop expertise. Motivation is a function of the students' perceptions of their prospects in the profession as well as access to inspiring resources and technology. This suggests the need to inspire students at the novice level, focusing on their prospects in the profession, so as to encourage them to develop higher levels of expertise.

The case is a little different for students who need to move from the advanced beginner stage to higher levels of expertise. The results of the study suggest the need spend more time at the presentation stage of their design tasks. Their tasks also need to develop their innovative and design media use skills. The low self-efficacy that differentiates advanced beginner design students also need to be addressed for them to move to higher levels of expertise. This calls for strategies that encourage the students to believe in their abilities.

Students at the highest level of design expertise in the study were differentiated by their abilities to integrate social, cultural and structural requirements as well as produce functional design. The development of these abilities requires that students be exposed to differing design projects over time. It is not surprising that competent design students spend more time designing each day. Another individual characteristic of students at the competent level of design expertise was their prior preparation in design. Prior trainings in fine arts and /or technical drawing appear to have helped these students develop their design expertise. It should be noted, however, that students of architecture undertake these subjects in their first and second years in architecture schools. This is to give students who may not have taken these subjects at the Secondary School Certificate level an advantage in the course. The environmental influences that differentiated students the competent level of expertise of the students in the study are design guidance and family support. This probably highlights the need for architectural design students receive guidance to aid their development of expertise. The place of family support, both emotional and financial, in the development of expertise corroborates the findings of Baker et al. (2003). As was noted by Dorst and Reymen (2004), the effectiveness of family support appears to be most prominent at the competent level of expertise. 


\section{Conclusion}

A major contribution of this study is in the area of empirical investigation of the inputs that contribute to the development of design expertise. These represent areas that mentors may emphasise to enhance the development of design expertise in architecture students. It has shown that expertise development is a function of individual, task and environmental characteristics, lending credence to the systems perspective of expertise. It has also shown that the inputs that differentiate individuals in one level of expertise from the other levels vary giving support to the contingency theory of expertise. This suggests that the inputs that need to be emphasised will vary with the current design expertise level of students. The study has identified the design abilities peculiar to the field of architecture as well as the conditions for design expertise. The categories of expertise amongst the architecture students who participated in the study were also identified.

Design tutors may need to focus on equipping students with knowledge on cultural and social requirements of designs by exposing such students to varying contexts. This is to enhance the ability of the students to integrate such knowledge in their designs. There is also need to give room for students to explore new solutions to develop their abilities to produce innovative designs. This may call for design briefs that challenge the students' creativity.

It has also been shown in this study that expertise in design goes beyond proficiency; it is also founded in passion. There is therefore a need for further study to investigate how the passion for a profession in design can be enhanced. The variance in the findings on the conditions for expertise also suggests the need to carry out study in other fields to identify points of convergence.

Novices in design were found in all the courses investigated including the final year of architecture study. This probably suggests that level of expertise should not be measured by years. Instead, future studies should categorise samples by their characteristics and not their years of study. The implication of this is that some graduates who are employed in practice are still beginning and may need more training and mentoring than others. This probably also suggests a need for more frequent internship because some students have not been able to attain the required expertise levels through formal training.

Although the design studio has been identified as a place for student-led problem solving which is expected to culminate in the development of design expertise, the findings of this study suggests the need to emphasise the use of learning resources to encourage novices to move to higher levels of expertise. It may be necessary for design tutors to design briefs in such a way that the students are required to consult these resources. Tutor-student relationships also need to be strengthened to foster enhanced development of design expertise. Other inputs that differentiate one level of expertise from others were identified. Design educators can harness these to encourage students to move to higher levels of expertise.

\section{References}

Adams, R. S., Turns, J., \& Atman, C. J. (2003). Educating effective engineering designers: The role of reflective practice. Design Studies, 24, 275-294. doi:10.1016/S0142-694X(02)00056-X

Alroomi, A., Jeoung, D. H. S., \& Oberlender, G. D. (2012). Analysis of cost-estimating competencies using Critical Matrix and Factor Analysis. Journal of Construction Engineering and Management, 138(11), 1270-1280.

Bakarman, A. (2005). Attitude, Skill, and Knowledge (ASK): A new model for design education. In the Proceeding of the Second CDEN Design Conference on Design Education, Innovation, and Practice, Kananaskis, Alberta, Canada. Retrieved from http://faculty.ksu.edu.sa/10177/Documents/ASK\%20Final\%20paper.pdf

Baker, J., \& Horton, S. (2004). A review of primary and secondary influences on sport expertise. High Ability Studies, 15(2), 211-228 
Baker, J., Horton, S., Robertson-Wilson, J., \& Wall, M. (2003). Nurturing sport expertise: Factors influencing the development of elite athlete. Journal of Sports Science and Medicine, 2(1), 19.

Bartholomew, D. (2008). Building on knowledge: Developing creativity and intellectual capital in the construction professions. Oxford, UK: Wiley-Blackwell.

Bayazit, N. (2004). Investigating design: A review of forty years of design research. Design Issues, 20(1), 16-30.

Beckman, S. L., \& Barry, M. (2007). Innovation as a learning process: Embedding design thinking. California Review Management, 50(1), 25-56.

Bonneville-Roussy, A., Lavigne, G. L., \& Vallerand, R. J. (2011). When passion leads to excellence: The case of musicians. Psychology of Music, 39(1), 123-138.

Boshuizen, H. P. A. (2003). How to bridge the gap between school and work. Inaugural Address Delivered at Public Acceptance of the Professorship in Educational Technology, Open Universiteit Nederland, January 31, 2003

Bjorklund, T. A., \& Eloranta, M. M. (2008). Fostering innovation: What can we learn from experts and expertise. Paper presented at $36^{\text {th }}$ SEFI Annual Conference. Retrieved from http://goo.gl/DBhvAV

Caley, M. J., O’Leary, R. C., Fisher, R., Low-Choy, S., Johnson, S., \& Mengersen, K. (2014). What is an expert? A systems perspective on expertise. Ecology and Evolution, 4(3), 231-242.

Cardella M. E., Atman C. J., \& Adams R. S. (2006). Mapping between design activities and external representations for engineering student designers. Design Studies, 27(1) 5-24.

Cross, N. G. (1990). The nature and nurture of design ability. Design Studies, 11(3), 127-140.

Cross, N. (2001). Design cognition: Results from protocol and other empirical studies of design activity. In C. Eastman, W. Newstatter, \& M. McCracken (Eds.), Design Knowing and Learning: Cognition in Design Education (pp. 79-103). Oxford, UK: Elsevier.

Cross, N. (2003). The expertise of exceptional designers. In N. Cross \& E. Edmonds (Eds.), Expertise in Design (pp. 23-35). Sydney, Australia: Creativity and Cognition Press, University of Sydney.

Cross, N. (2004). Expertise in design: An overview. Design Studies, 25(5), 427-441.

Cross, N., \& Lawson, B. (2005). Studying outstanding designers. In J. S. Gero \& N. Bonnardel (Eds.), Studying designers '05 (pp. 283-288). Sydney, Australia: Key Centre of Design Computing and Cognition, University of Sydney.

Dorst, K. (2011). The core of design thinking and its application. Design Studies, 32(6), 521-532.

Dorst, K., \& Cross, N. (2001). Creativity in the design process: Co-evolution of problem solution, Design Studies, 22: 425 - 437.

Dorst, K., \& Reymen, I. (2004). Levels of expertise in design education. International Engineering and Product Design Education Conference, September 2-3, Delft, Netherlands.

Dreyfus, H. L., \& Dreyfus, S. E. (1986). Mind over machine: The power of human intuitive expertise in the era of the computer. New York: Free Press.

Ericsson, K. A. (2006), the influence of experience and deliberate practice on the development of superior expert performance. The Cambridge Handbook of Expertise and Expert Performance (pp. 685-706). New York: Cambridge University Press.

Ericsson, K. A., Krampe, R., \& Tesch-Romer, C. (1993). The role of deliberate practice in the acquisition of expert performance. Psychological Review, 100, 363-406.

Ericsson, K. A., \& Lehmann, A. C. (1996). Expert and exceptional performance: Evidence of maximal adaptation to task constraints. Annual Review of Psychology, 47, $273-305$. 
Ericsson, K. A., \& Ward, P. (2007). Capturing the naturally occurring superior performance of experts and exceptional performance. Current Directions in Psychological Science, 16(6), 346350.

Germain, M. (2008). Traits and skills theories as the nexus between leadership and expertise: reality or fallacy? Retrieved from http://files.eric.ed.gov/fulltext/ED501636.pdf

Gobet, F. (1998). Expert memory: A comparison of four theories. Cognition, 66, 115-152.

Gobet, F. (2012). Deliberate practice and its role in expertise development. In N. M. Seel (Ed.), Encyclopedia of the Sciences of Learning. New York: Springer.

Gobet, F. (2013). Expertise vs. talent. Talent Development and Excellence, 5, 59-70.

Gobet, F., \& Campitelli, G. (2007). The role of domain specific practice, handedness and starting age in chess. Development Psychology, 43, 159-172.

Guindon, R. (1990). Designing the design process: Exploiting opportunistic thoughts. Human Computer Interaction, 5, 305 - 344.

Johnson, K. (2005). The general study of expertise, In K. Johnson (Ed.), Expertise in Second Language Learning and Teaching (pp. 11-33). New York: Palgrave Macmillan.

Jungersen, U., \& Hansen, P. H. K. (2014) Design a municipality. In M. Laakso, \& K. Ekman (Eds.), Proceedings of Norddesign 2014 Conference (pp. 610-619). Retrieved from http://vbn.aau.dk/files/207631225/Jungersen_Hansen_2014_Designing_a_Municipality.pdf

Kirschner, P., Carr, C., Van Merriënboer, J., \& Sloep, P. (2002). How expert designers design: Priorities in designing competence-based learning. Performance Improvement Quarterly, 15(4), 86-104.

Lazzara, E. H., Dietz, A. S., Weaver, S. J., Pavlas, D., Heyne, K., Salas, E., \& Ramachandran, S. (2010). Guidelines for training adaptive expertise. In Proceedings of the Human Factors and Ergonomics Society. (Vol. 3, pp. 2294-2298). doi: 10.1518/107118110X12829370266400

Lawson, B., \& Dorst, K. (2005). Acquiring design expertise. In J. S. Gero \& M. L. Maher (Eds.), Computational and Cognitive Models of Creative Design VI (pp. 213-229). Sydney, Australia: Key Centre of Design Computing and Cognition, University of Sydney.

Lawson, B., \& Dorst, K. (2009). Design expertise. London: Architectural Press.

Mieg, H. A. (2009). Two factors of expertise? Excellence and professionalism of environmental experts. High Ability Studies, 20(1), 91-115.

Meijers F., \& Kuijpers M. (2014). Career learning and career learning environment in Dutch higher education. Journal of Applied Research in Higher Education, 6(2), 295-313.

Moon, T. K., Kim, E. J., \& You Y. (2013). Study on expertise development process based on Arete. International Journal of Information and Education Technology. 3(2), 226-230.

Peeters, M. A. G., van Tuijl, H. F. J. M., Reymen, I. M. M. J., \& Rutte, C. G. (2007). The development of a design behaviour questionnaire for multidisciplinary teams. Design Studies, 28, 623-643.

Phillips E., Keith D., Renshaw I., \& Portus M. (2010). Expert performance in sport and the dynamics of talent development. Sports Medicine, 40(4), 271-283.

Popovic, V. (2004). Expertise development in product design - Strategic and domain-specific knowledge connections. Design Studies, 25(2), 527-545.

Reimer, Y. J., \& Douglas, S. A. (2003). Teaching HCI design with the studio approach. Computer Science Education, 13(3), 191-205.

Smith, K. M. (2015). Conditions influencing the development of design expertise: As identified in interior design student accounts. Design Studies, 36, 77-98. 
Sternberg, R. J. (1999). Intelligence as developing expertise. Contemporary Educational Psychology, 24, 359-375

Svihla, V., Petrosino, A., \& Diller, K. (2007). Distributed expertise and authenticity in the development of design expertise. Paper presented at the International Conference on Engineering Education (ICEE), Coimbra Portugal. September 3-7, 2007.

Tagg, J. (2007). Learning outcomes and the development of expertise. On the Horizon, 15(2), 8998.

Zanon, B. (2014) Technical expertise: Changing paradigms and practices in the Italian experience. Planning, Practice and Research, 29(1), 75-95.

Copyright @ 2017 Adedapo Adewunmi Oluwatayo, Isidore Ezema, and Akunnaya Opoko 